\title{
A Structural Equation Model of The Relationships Between Psychological Distress, HIV Status And Other Exogenous Factors In South Africa
}

Nolusindiso Ncitakalo ( $\sim$ nncitakalo@wsu.ac.za )

Walter Sisulu University

Lovemore Nyasha Sigwadhi

Stellenbosch University

Musawenkosi Mabaso

Human Sciences Research Council

John Joska

University of Cape Town

Leickness Simbayi

University of Cape Town

Research Article

Keywords: Psychological distress, HIV status, South Africa, Structural Equation Model

Posted Date: January 24th, 2022

DOI: https://doi.org/10.21203/rs.3.rs-1266192/v1

License: (9) This work is licensed under a Creative Commons Attribution 4.0 International License. Read Full License 


\section{Abstract}

Background: Mental disorders like depression and anxiety are more prevalent in people living with HIV (PLHIV) than in the general population. Improved understanding of the relationship between mental disorders and HIV is important for designing interventions for this group. However, the relationship between mental disorders and HIV is complex and bidirectional. This paper explores the interrelationships between the psychological distress as measured by depression and anxiety symptoms, HIV status and other exogenous variables such as demographic, HIV and health-related variables using structural equation modelling.

Methods: This secondary data analysis used the 2012 South African population-based household survey on HIV collected using a multi-stage stratified cluster sampling design. Generalized structural equation modelling (G-SEM) path analysis was used to explore the direct and indirect relationships of sociodemographic, health and HIV-related factors with psychological distress using HIV status as a moderator variable.

Results: A total of 20083 participants were included in the study, 21.7\% reported psychological distress, of whom (12.6\%) were HIV positive. In the final path model with HIV status as a moderator, psychological distress was significantly more likely among age group 25-49 years (AOR: 1.4 [95\% Cl: 1.3-1.6]), age 50 years and older, (AOR: 1.4 [95\% Cl: 1.2-1.6]), females (AOR:1.6 [95\% Cl: 1.4-1.8]), high risk drinkers (AOR: 1.9 [1.6-2.2]) hazardous drinkers (AOR: 4.4 [95\% Cl: 3.1-6.3]), ever tested for HIV (AOR: 1.2 [95\% Cl: 1.11.3]). Psychological distress was significantly less likely among the married [AOR: 0.8 (0.7-0.9)], other race groups [AOR: $0.5(0.5-0.6)$ ], those with secondary level education (AOR: 0.9 [95\% Cl: 0.8-0.9]), and tertiary level education (AOR: 0.7 [95\% Cl: 0.6-0.9]), those from rural informal [AOR: 0.8 (0.7-0.9)], and rural formal [AOR: $0.8(0.7-0.9)$ ] areas and those who rated their health as excellent/good [AOR: $0.4(0.4-0.5)]$.

Conclusion: The findings highlight the mediating role of HIV positive status in producing psychological distress especially among young people, males and those with no education and / or low education attainment. Understanding this complex relationship is important for developing interventions to prevent psychological distress especially among PLHIV.

\section{Introduction}

The comorbidity of HIV and mental disorders has become an increasing major public health challenge and is a substantial burden to society [1]. Common mental disorders are recognized as frequent psychiatric comorbid conditions among PLHIV [2]. Depression is found to be more common in people living with HIV compared with prevalence estimates in the general population [3], directly impacting their quality of life and impeding their enrolment and retention in treatment [4]. Research studies have shown that the causes of mental disorders are multi factorial and include among others biological, social, and economic factors [5]. 
There is considerable evidence that common mental disorders are distributed according to economic gradient across society and that the poor and disadvantaged suffer disproportionately from common mental disorders and their adverse consequences [5]. Moreover, Knifton and Inglis argue that the mental health of individuals is shaped by the social, environmental and economic conditions in which they are born, grow, work and age [6]. In addition, there is consistent evidence that experience of socioeconomic disadvantage, including unemployment, low income, poverty, debt and poor housing, is associated with poorer mental health $[7 ; 8]$. A systematic review of social determinants of mental disorders by Lund and colleagues highlighted that these determinants of mental disorders are the social and economic conditions that have a direct influence on the prevalence and severity of mental disorders in men and women [9].

PLHIV are additionally affected due to lack of social support, poor self-esteem, stigma, and discrimination $[10 ; 11]$. This, in turn, predisposes them to psychological problems like depression and anxiety at greater rates than the general population [12;13]. In addition, HIV-related stigma has been recognised as a fundamental cause of health inequalities [14]. HIV-related stigma has been observed as a contributing factor to mental health and substance use problems among people living with HIV [15]. In addition, HIV testing, and awareness of HIV positive status affects mental capacity to cope especially because of social stigma associated with living with HIV [16]. Since HIV stigma and discrimination affect the emotional well-being and mental health, these feelings can keep people from getting tested and treated for HIV [16; 17].

Reducing the burden of comorbid mental disorders is key to achieving the UNAIDS care cascade goals of 95-95-95 [18]. Furthermore, mental disorders have been recognized as a risk factor for HIV transmission, through their effects on various aspects of sexual behaviour [19]. Moreover, both mental disorders and substance use disorders are known predictors of poor HIV disease management including suboptimal adherence to antiretroviral therapy (ART) and faster disease progression [20; 21]. Mental disorders can increase risk of HIV acquisition through both direct and indirect pathways [22]. Several studies have shown that sexually active people with mental disorders have higher risk sexual behavior, including inconsistent condom use, having multiple sexual partners, trading sex, and drinking alcohol before sex [23-25].

Previous research studies have shown that the relationship between mental disorders and HIV/AIDS is complex and bidirectional. Mental disorders are found to play a critical role in HIV acquisition across populations, while on the other hand, the stress of living with HIV can negatively affect one's mental health. The underlying factors remain poorly understood. Many factors contribute to the high comorbidity of HIV and mental health conditions. Studies have used structural equation model (SEM) to understand this complex relationship by investigating a conceptual model of the pathways linking wellbeing including mental health, social support, self-rated health and HIV-related stigma [26]. SEM has been utilized to develop psychological model to predict antiretroviral therapy medication adherence behavior [27]. Others have used SEM to investigate factors associated with HIV risk behaviors and mental health 
and examine the role of intersecting stigmas [28]. However, there is paucity of large population-based studies of complex interactions between psychological distress, HIV status and predisposing factors.

This paper therefore explores the relationships between psychological distress, HIV status and exogenous variables using the structural equation modelling in South Africa using the 2012 national householdbased population survey on HIIV. Structural equation modelling was used to test hypothesized pathways between psychological distress, HIV status and associated socio-demographic, health and HIV related factors.

\section{Methodology}

\section{Data source}

This secondary data analysis used the 2012 South African population-based household survey on HIV [29]. The data was collected using a multi-stage stratified cluster sampling design. A total of 1000 census enumeration areas (EAs) from the 2001 population census in South Africa were randomly selected using probability proportional to size and stratified by province, locality type and race in urban areas from a database of 86,000 EAs. In each sampled EA a total of 15 visiting points (VPs) or households were used as secondary sampling units. Persons of all ages living in South African households and hostels were eligible to participate and formed the ultimate sampling unit.

Four questionnaires were administered in the survey to solicit information including among other sociodemographic characteristics, HIV knowledge, self-received risk of being infected with HIV and HIV related stigma and discrimination against PLHIV. In addition, blood specimens were collected from consenting individuals for HIV testing. The current study is based on a sub-sample of youth and adult individuals 15 years and older who responded to the questions on psychological distress.

\section{Measures}

\section{Endogenous variables}

Psychological distress was the observed endogenous variable based on the respondent's experience of depressive and anxiety disorders measured using the Kessler 10 scale [30], which consists of the following 10 items that describe how they felt during the previous 30 days: How often did you feel: Tired out for no good reason? So nervous that nothing could calm you down? Hopeless; Restless or fidgety: So restless that you could not sit still; Depressed? That everything was an effort? So sad that nothing could cheer you up? Worthless?' Responses to these items were recorded using a 5-point Likert scale ( $1=$ never, $2=$ rarely, $3=$ some of the time, $4=$ most of the time, $5=$ all of the time). The scores from these responses were then summed to calculate a total score indicating whether the respondents were likely to experience psychological distress. The scores were then dichotomized into a binary outcome those who scored $<19$ absence of psychological distress $=0$ ) and those who scored $\geq 20$ (presence of psychological distress $=1$ ). 


\section{Exogenous variables}

The selected exogenous variables included a set of demographic variables such as age (15-24, 25-34, 3549, 50 years and older), sex (male and female), race (black African and other races), educational level (primary/ no education, secondary, tertiary), employment status (unemployed and employed), locality type (urban formal, urban informal, rural informal/ tribal areas, rural formal/ farm areas) and asset based socio-economic status (low and high). This also included HIV-related variables such as self-perceived risk of HIV infection (no and yes), HIV knowledge and myth rejection (no and yes), ever tested for HIV (no and yes), awareness of HIV status based on the question "Have you been told/informed of the result of your most recent test? (no and yes), external HIV-related stigma (high and low), and self-rated health (fair/poor and good/excellent).

\section{Mediator variable}

HIV status was included as a mediator in the relationship between the endogenous and exogenous variables. Although HIV testing was anonymous and returning of the results optional and dependent on study participant, it is assumed that the majority of study participants were aware of their HIV status, and this is hypothesized that HIV status mediates the effects of demographic, health and HIV-related variables on psychological distress.

\section{Conceptual model and analysis}

Generalized structural equation modelling (G-SEM)-path analysis was used to explore the direct and indirect relationships of key variables with psychological distress using HIV status as a mediator variable (see Figure 1). The conceptual model follows the Fundamental Causes Theory which suggests that individuals' health condition is influenced by contextual factors [31] such as demographics (age, gender, race, locality), socio-economic status (educational level, employment), social contexts (social support), and persistent health disparities (self-rated health, HIV related stigma). This model also includes health and HIV-related factors such alcohol use AUDUT score, self-rated health, HIV testing history (ever had an HIV test), awareness of HIV status, self-perceived risk of HIV, and experiences of externalised HIV-related stigma.

G-SEM was used to measure linear and non-linear causal relationships among selected variables, while simultaneously accounting for measurement error. G-SEM is a combination of three statistical techniques: multiple regression, path analysis, and factor analysis. Its purpose was to determine the extent to which a proposed theoretical model, expressed by a set of relations among different constructs, is supported by the collected data. Mediation analysis for each variable was performed and a final path analysis including the goodness of fit was conducted. Goodness-of-fit chi square test, root mean square error of approximation (RMSEA), Tucker-Lewis's index (TLI), and comparative fit index (CFI) were used to assess the model fit. All variables with $p<0.05$ were considered statistically significant and statistical analyses were performed using Stata (V.16, Stata Corp, College Station, Texas, USA) statistical software. 


\section{Results}

\section{Sample characteristics and psychological distress}

Table 1 shows the characteristics of the study sample and psychological distress. Out of the 20083 participants, $22.6 \%$ had psychological distress, of whom (12.6\%) were HIV positive. Psychological distress was significantly higher among those aged $25-49$ years (44.6\%), among females $(57.7 \%)$, those not married (66.8\%), African (71.2\%), those with secondary level education (67.5\%), those from formal urban areas (51.5\%), those who abstained from alcohol (66.6\%), those who reported good/excellent selfrated health (64.1\%), those who ever tested for HIV (66.6\%), those not aware of their HIV status (58.1\%), those who perceived themselves as being at risk of HIV (74.3\%).

Table 2 shows how the independent variables influence psychological distress (Step 1 in establishing mediation). Most independent variables significantly influenced psychological distress. Those aged 25 to 45 years, 50 years and older, females and those residing in rural formal and rural informal areas were significantly more likely to develop psychological distress compared to their counterparts. Those who drink alcohol (low risk drinker, high risk drinker and hazardous drinkers), and those who ever tested for HIV, were also significantly more likely to develop psychological distress compared to their counterparts. In addition, those married, other race groups, those with secondary and tertiary level education, the employed, and those from rural formal and rural informal areas were significantly less likely to develop psychological distress compared to their counterparts.

Table 3 shows how the independent variables influence the mediator variable HIV status (Step 2 in establishing mediation). Those aged 25 to 45 years, 50 years and older, females, and those residing in rural formal and rural informal areas were significantly more likely to be HIV positive compared to their counterparts. Those who ever tested for HIV were also significantly more to HIV positive compared to their counterparts. Furthermore, those married, other race groups, those with tertiary level education, the employed and those residing in rural formal and rural informal areas were significantly less likely to develop psychological distress compared to their counterparts. Those who rated their health as excellent/good were also significantly less likely to be HIV positive compared to their counterparts.

Figure 2 shows how the mediator variable influences psychological distress (Step 3 in establishing mediation). The final model shows that HIV significantly influenced psychological distress levels in the third equation. The independent variables and HIV status entered into the model as predictors, were significantly related to the independent variables, hence the first condition satisfied. A strong association between most of the independent variables and psychological distress was observed, thus second condition satisfied. HIV status was a strong predictor of psychological distress therefore third condition satisfied.

In the final model those aged 25 to 45 years and 50 years and older, females and those residing in rural areas were significantly more likely to develop psychological distress compared to their counterparts. Those who ever tested for HIV and those with experiences of internalised stigma were also significantly 
more likely to develop psychological distress compared to their counterparts. Furthermore, those married, other race groups, the employed, those with tertiary level education, those who rated their health as excellent/good, and those who were aware of their HIV status were significantly less likely to develop psychological distress compared to their counterparts.

Introduction of HIV status into the model weakened the effect of some independent variables thus fourth condition satisfied. This confirms that HIV status mediates the effect of independent variables towards psychological distress. The likelihood ratio test shows that the $p$-value is less than 0.05 suggesting that model 2 is better than the previous model, and that our model is a good fit (Table 4). RMSEA assessed the population error, and it was very small close to zero suggesting a good fit of our model. The same idea was supported by the $p$-close of 1 . TLI value greater than 0.95 provide evidence of the acceptance of model fit.

\section{Discussion}

In this study, we examined the interrelationships between psychological distress, HIV status and associated factors among youth and adults 15 years and older using data from a nationally representative cross-sectional survey. This is the first study that explored the complex and bidirectional relationship between psychological distress and HIV status and associated predisposing factors to both conditions. The prevalence of psychological distress among the study population was $21.7 \%$, and of these $12.6 \%$ were HIV positive.

The final model with HIV status as a mediator variable showed that other than HIV infection, psychological distress was significantly associated with older age group than youth (15-24 years and female. There is lack of consistent results about how age affects depression and anxiety [32]. Contrary to current findings, other studies found lower level of distress in older age groups [33]. In South Africa, HIV is a major problem among the youth especially among females [34]. Other studies have also found a higher prevalence of psychological distress among women living with HIV compared to men [35-37]. It is likely therefore that differential patterns of exposure to HIV predispose these population groups to psychological distress. These observations emphasize the need for differentiated care and targeted interventions to support these vulnerable groups.

Furthermore, the model showed that heavy alcohol intake was associated with psychological distress. Other studies have also found that harmful lifestyle factors such as excessive drinking in PLHIV increased risk for anxiety and depressive symptoms [38]. This suggests that interventions should mitigate the effects of adverse lifestyle factors such as alcohol abuse in preventing psychological distress especially among PLHIV. The current findings therefore highlight the importance of screening for alcohol abuse in this group.

In agreement with current findings, other studies found that HIV-infected individuals with psychological distress were more likely to have had an HIV test, partly due to worry arising from the knowledge of potentially being infected [39]. Evidence shows that the impact of being diagnosed with HIV infection, 
associated stigma, social isolation, and discrimination may all lead to depressive disorders among PLHIV. However, others argue that symptoms of depression and distress are common among persons seeking HIV testing and are therefore not a consequence of an HIV-positive test result [40]. Nevertheless, the findings of this study support proposals for greater integration of mental health services with HIV testing services especially in populations suffering from high levels of psychological distress.

The finding that marriage is protective of psychological distress is consistent with other studies indicating a benefit of marriage for mental health partly due to family/social support since marriage protects against feelings of loneliness [41]. Other studies also found that those in marriage suffer less psychological distress and have higher levels of emotional and psychological well-being than those who are single, divorced, or cohabiting [42]. The observed positive influence of marriage on psychological distress highlights the importance of improving marital quality to promote mental health.

Differences in psychological distress were also observed across race groups. The observed differences in psychological distress between Black Africans and other race groups in the context of HIV can be attributed to the racial disparities rooted in structural and contextual inequalities that sustain the HIV epidemic among Black Africans [43]. Other studies also observed that socio-economic resources help explain differences in psychological distress between Africans and other race groups [44]. This suggest that addressing social and resource inequality such as access to basic services, education, and employment will in a way address social stressors and mitigate psychological distress especially among PLHIV.

The finding of protective effects of socio-economic status indicators such as education attainment and employment against psychological distress is partly because educational achievement has a positive effect on outlook in life and increase self-efficacy, which in turn helps people cope with life's problems and stresses [45]. On the other hand, employment promotes positive emotions due to social security since jobs provide resources that can mitigate stress, support healthy lifestyles and thereby promote mental health [46]. Therefore, policies promoting access to education and reducing unemployment may be important for mitigating the impact of psychological distress especially among PLHIV.

The findings also suggest that the relationship between HIV and psychological distress differs across urban and rural settings. The currents results suggest that residing in rural areas is protective of psychological distress while other studies have observed that people in rural areas present with higher levels of symptoms of psychological distress than their urban counterparts [47]. In South Africa, the high levels of psychological distress may be linked to the persistently high level of HIV prevalence in urban settings [29; 34]. This highlights the importance of integrating mental health care in HIV-related care in areas where most of the population live with HIV.

\section{Limitations}


While SEM remains a powerful tool for exploratory analysis and for the hypothesis-generating process, the analysis may be limited by the difficulty to describe the relationship between HIV and co-occurring mental disorders that may be present prior to HIV diagnosis. The analysis may also be limited by the possibility that other unmeasured variables may have affected the observed relationship between endogenous and exogenous variables and between endogenous variables. In addition, social desirability response bias due to self-report may have influenced some of the results. The cross-sectional nature of the study prevents causal inference limiting our understandings of the exact nature of the relationship between HIV status and psychological distress. Causal pathways could be better clarified with a longitudinal study design.

\section{Conclusion}

HIV status was found to be an influencing factor that had a direct effect on psychological distress. We therefore conclude that HIV status mediates the relationship between psychological distress and the exogenous factors such as age, sex, race, education and employment. It is important to buffer the impact of these interrelations through effective psychological distress interventions to improve the health and wellbeing of PLHIV in South Africa. Avenues of intervention may include provision of social support, selfesteem enhancement, and improving coping skills. The format and content of such interventions should be context specific. Finally, integration of mental health and HIV services is needed.

\section{Declarations}

\section{Ethics approval and consent to participate}

The study protocol was approved by the HSRC's Research Ethics Committee (REC: 5/17/11/10) and the Associate Director of Science of the National Center for HIV and AIDS, Viral Hepatitis, STD and TB Prevention at the Centers for Disease Control and Prevention (CDC) in Atlanta, GA, USA.

\section{Consent for publication}

Not applicable.

\section{Availability of data and materials}

The datasets used and/or analysed during the current study are available from the corresponding author on reasonable request.

\section{Competing interests}

The authors declare that they have no competing interests.

\section{Funding}


The data used comes from a study supported by the President's Emergency Plan for AIDS Relief (PEPFAR), whose funding we received through a cooperative agreement (Grant Number 5U2GPS000570) with the USA's Centers for Disease Control and Prevention (CDC).

\section{Authors' contributions}

NN conceptualized the study, developed the methodology, conducted the analysis, and wrote the first draft of the manuscript. LNS developed the study model and assisted in data analysis. MM contributed to data analysis and assessed the quality. LS and $\mathrm{JJ}$ reviewed the manuscript and ensured data quality. All authors read and approved the final manuscript.

\section{Acknowledgements}

The data used in this paper were collected with support of the President's Emergency Plan for AIDS Relief (PEPFAR) through the CDC under the terms of 5U2GGH000570. Additional support was also received from the Bill \& Melinda Gates Foundation, the South African National AIDS Council (SANAC) and the United Nations Children's Fund (UNICEF). The contents of the paper are solely the responsibility of the authors and do not necessarily represent the official views of CDC or any of the funders alike. The original data are archived and accessible from http://curation.hsrc.ac.za/doi10.14749-1500530684.

\section{References}

1. Dwyer-Lindgren L, Cork MA, Sligar A, Steuben KM, Wilson KF, Provost NR, Mayala BK, VanderHeide JD, Collison ML, Hall JB. Mapping HIV prevalence in sub-Saharan Africa between 2000 and 2017. Nature. 2019; 570:189-193.

2. Belayneh Z, Mekuriaw B, Mehare T, Shumye S, Tsehay M. Magnitude and predictors of common mental disorder among people with HIV/ AIDS in Ethiopia: a systematic review and meta-analysis. BMC Public Health. 2020; 20:689.

3. Lofgren SM, Bond DJ, Nakasujja N, Boulware DR. Burden of depression in outpatient HIV-infected adults in Sub-Saharan Africa; Systematic Review and Meta-analysis. AIDS Behav. 2020; 24:17521764.

4. Kulisewa K, Stockton MA, Hosseinipour MC, Gaynes BN, Mphonda S, Udedi MM, et al. The Role of Depression Screening and Treatment in Achieving the UNAIDS 90-90-90 Goals in Sub-Saharan Africa. AIDS Behav. 2019; 23(2):153-161.

5. World Health Organization and Calouste Gulbenkian Foundation. Social determinants of mental health. Geneva, World Health Organization, 2014.

6. Knifton L, Inglis G. Poverty and mental health: policy, practice and research implications. BJPsych bulletin. 2020; 44(5): 193-196.

7. Platt S, Stace S, Morrissey J (eds). Dying from inequality: Socioeconomic Disadvantage and Suicidal Behaviour. Samaritans, London. 2017. 
8. Silva M, Loureiro A, Cardoso G. Social determinants of mental health: a review of the evidence. Eur J Psychiatry. 2016; 30:259-292.

9. Lund L, Brooke-Sumner C, Baingana F, Baron EC, Breuer E, Chandra P. Social determinants of mental disorders and the Sustainable Development Goals: a systematic review of reviews. Lancet Psychiatry. 2018; 5: 357-69.

10. Arias-Colmenero T, Pérez-Morente MÁ, Ramos-Morcillo AJ, Capilla-Díaz C, Ruzafa-Martínez M, HuesoMontoro C. Experiences and Attitudes of People with HIV/AIDS: A Systematic Review of Qualitative Studies. Int J Environ Res Public Health. 2020;17(2):639.

11. Clum G, Chung SE, Ellen JM. Mediators of HIV-related stigma and risk behavior in HIV infected young women. AIDS Care. 2009; 21(11): 1455-1462.

12. Obadeji A, Ogunlesi AO, Adebowale TO. Prevalence and predictors of depression in people living with HIV/AIDS attending an outpatient clinic in Nigeria, Iranian Journal of Psychiatry and Behavioral Sciences. 2014; 8(1):26-31.

13. Simbayi LC, Kalichman S, Strebel A, Cloete A, Henda N, Mqeketo A, Internalized stigma, discrimination, and depression among men and women living with HIV/AIDS in Cape Town, South Africa. Social Science \& Medicine. 2007; 64(9):1823-1831.

14. Hat-zenbuehler ML, Phelan JC, Link BG. Stigma as a fundamental cause of population health inequalities. Am J Public Health. 2013; 103:813-821.

15. Felker-Kantor EA, Wallace ME, Madkour AS, Duncan DT, Andrinopoulos K, Theall K. HIV stigma, mental health, and alcohol use disorders among people living with HIV/AIDS in New Orleans. J Urban Health. 2019; 96(6):878-888.

16. Armoon B, Higgs P, Fleury MJ. Bayat AH, Moghaddam LF, Byan A, et al. Socio-demographic, clinical and service use determinants associated with HIV related stigma among people living with HIV/AIDS: a systematic review and meta-analysis. BMC Health Serv Res. 2021; 21:1004.

17. Worku MG, Teshale AB, Tesema GA. Prevalence and Associated Factors of HIV Testing Among Pregnant Women: A Multilevel Analysis Using the Recent Demographic and Health Survey Data from 11 East African Countries. HIV AIDS (Auckl). 2021; 11(13): 181-189.

18. UNAIDS. Thematic segment: Mental health and HIV/AIDS - promoting human rights, an integrated and person-centred approach to improving ART adherence, well-being and quality of life. Geneva, Switzerland, 2018.

19. Besa NM, Paul R, Hachaambwa L. Psychiatric symptoms among an HIV positive Urban Population in Lusaka, Zambia. Medical Journal of Zambia. 2015; 42(2):84-89.

20. Rueda S, Mitra S, Chen S, Gogolishvili D, Globerman J, Chambers L, et al. Examining the associations between HIV-related stigma and health outcomes in people living with HIV/AIDS: a series of metaanalyses. BMJ Open. 2016; 6(7): e011453. 10.

21. Vanable P, Carey M, Blair D, Littlewood R. Impact of HIVrelated stigma on health behaviors and psychological adjustment among HIV-positive men and women. AIDS Behav. 2006; 10(5):473-82. 
22. Remien RH, Stirratt MJ, Nguyen N, Robbins RN, Pala AN, Mellins CA. Mental health and HIV/AIDS: the need for an integrated response. AIDS. 2019; 33(9):1411-1420.

23. Abayomi O, Adelufosi A, Adebayo P, Ighoroje M, Ajogbon D, Ogunwale A. HIV risk behavior in persons with severe mental disorders in a psychiatric hospital in Ogun, Nigeria. Ann Med Health Sci Res. 2013; 3:380-384.

24. Bonfils KA, Firmin RL, Salyers MP, Wright ER. Sexuality and intimacy among people living with serious mental illnesses: factors contributing to sexual activity. Psychiatr Rehabil J. 2015; 38:249255.

25. Guimaraes MD, McKinnon K, Cournos F, Machado CJ, Melo AP, Campos LN, et al. Correlates of HIV infection among patients with mental illness in Brazil. AIDS Care. 2014; 26:505-513.

26. Logie CH, Jenkinson JIR, Earnshaw V, Tharao W, Loutfy MR. A Structural Equation Model of HIVRelated Stigma, Racial Discrimination, Housing Insecurity and Wellbeing among African and Caribbean Black Women Living with HIV in Ontario, Canada. PLoS ONE. 2016; 11(9): e0162826.

27. Sagarduy JLY, López JAP, Ramírez MTG, Dávila LEF. Psychological model of ART adherence behaviors in persons living with HIV/AIDS in Mexico: a structural equation analysis. Rev Saude Publica. 2017; 51:81.

28. Zhao Y, Rao A, Wirtz, AL et al. A structural equation model of factors associated with HIV risk behaviors and mental health among men who have sex with men in Malawi. BMC Infect Dis. 2020; 20: 591.

29. Shisana O, Rehle T, Simbayi LC, Zuma K, Jooste S, Zungu N, et al. South African National HIV Prevalence, Incidence and Behaviour Survey, 2012. Cape Town, HSRC Press. 2014.

30. Kessler RC, Barker PR, Colpe LJ, Epstein JF, Gfroerer JC, Hiripi E. Screening for serious mental illness in the general population. Archives Of General Psychiatry. 2003; 60(2):184-189.

31. Link BG, Phelan J. Social conditions as fundamental causes of disease. Journal of health and social behavior. 1995; 80-84.

32. Drapeau A, Marchand A, Forest C. Gender differences in the age-cohort distribution of psychological distress in Canadian adults: findings from a national longitudinal survey. BMC Psychol. 2014; 2: 25.

33. Jorm AF, Windsor TD, Dear KBG, Anstey KJ, Christensen H, Rodgers B: Age group differences in psychological distress: the role of psychosocial risk factors that vary with age. Psychlogical Medicine. 2005, 35: 1253-1263.

34. Simbayi LC, Zuma K, Zungu N, Moyo S, Marinda E, Jooste S, et al. South African National HIV Prevalence, Incidence, Behaviour and Communication Survey, 2017. Cape Town: HSRC Press. 2019.

35. Ayano G, Tulu M, Haile K, Assefa D, Habtamu Y, Araya G, Yohannis Z. A systematic review and metaanalysis of gender difference in epidemiology of HIV, hepatitis $B$, and hepatitis $C$ infections in people with severe mental illness. Ann Gen Psychiatry. 2018; 17(16).

36. Garriga C, Gutiérrez Trujillo L, Del Romero J, Montero M, Pérez-Elías MJ, Dante Culqui Lévano D, et al. Psychological distress in women and men living with HIV in Spain: a cross-sectional telephone survey. Evid Based Ment Health. 2020; 23:91-99. 
37. Waldron EM, Burnett-Zeigler I, Wee V, Ng YW, Koenig LJ, Pederson AB, Tomaszewski E, Miller ES. Mental Health in Women Living With HIV: The Unique and Unmet Needs. J Int Assoc Provid AIDS Care. 2021; 20.

38. Piumattia G, Lietz F, Aresi G, Bjegovic-Mikanovi V. Alcohol use, psychological distress, and subjective well-being among young adult university students: A cross-national study between Serbia and Italy. Journal of Ethnicity in Substance Abuse. 2019; 18(4):511-529.

39. Tlhajoane M, Eaton JW, Takaruza A, et al. Prevalence and Associations of Psychological Distress, HIV Infection and HIV Care Service Utilization in East Zimbabwe. AIDS Behav. 2018; 22(5):14851495.

40. Kagee A, Saal W, Bantjes J. Distress, depression and anxiety among persons seeking HIV testing. AIDS Care. 2017; 29(3): 280-284.

41. Ben-Zur H. Loneliness, optimism, and well-being among married, divorced, and widowed individuals. J Psychol. 2018; 146:23-36.

42. Scott KM, Wells JE, Angermeyer $M$, et al. Gender and the relationship between marital status and first onset of mood, anxiety and substance use disorders. Psychol Med. 2010; 9:1495-505.

43. Mabaso M, Makola L, Naidoo I, Mlangeni LL, Jooste S, Simbayi L. HIV prevalence in South Africa through gender and racial lenses: results from the 2012 population-based national household survey. Int J Equity Health. 2019; 18,167.

44. Jackson PB, Williams DR, Stein DJ, Herman A, Williams SL, Redmond DL. Race and psychological distress: the South african stress and health study. J Health Soc Behav. 2010; 51(4):458-477.

45. Muñozes IG, Santos-Lozada AR. Educational attainment and psychological distress among workingage adults in the United States. SSM - Mental Health. 2021; 1(100003).

46. WHO. Mental health and work: Impact, issues and good practices. World Health Organisation, Geneva: Switzerland; 2000.

47. Basta TB, Shacham E, Reece M. Symptoms of psychological distress: a comparison of rural and urban individuals enrolled in HIV-related mental health care. AIDS Patient Care STDS. 2009; 23(12):1053-1057.

\section{Tables}

Table 1: Socio-demographic, health and HIV-related characteristics of the study sample. 


\begin{tabular}{|c|c|c|c|}
\hline Variables & Study sample & Psychological distress & p-value \\
\hline Age group (years) & Total (\%) & $\mathrm{n}(\%)$ & \\
\hline 15 to 24 & $5716(28.5 \%)$ & $1020(22.4 \%)$ & $<0.001$ \\
\hline 25 to 49 & 8573 (42.7\%) & $2029(44.6 \%)$ & \\
\hline $50+$ & $5789(28.8 \%)$ & $1505(33.0 \%)$ & \\
\hline \multicolumn{4}{|l|}{ Sex } \\
\hline Male & $8503(42.3 \%)$ & $1511(33.2 \%)$ & $<0.001$ \\
\hline Female & $11580(57.7 \%)$ & $3045(66.8 \%)$ & \\
\hline \multicolumn{4}{|l|}{ Marita status } \\
\hline Not Married & $13235(66.8 \%)$ & 3149 (70.3\%) & $<0.001$ \\
\hline Married & $6568(33.2 \%)$ & $1332(29.7 \%)$ & \\
\hline \multicolumn{4}{|l|}{ Race group } \\
\hline African & 12097 (60.3\%) & $3244(71.2 \%)$ & $<0.001$ \\
\hline Other & $7970(39.7 \%)$ & $1309(28.8 \%)$ & \\
\hline \multicolumn{4}{|l|}{ Education level } \\
\hline No education/Primary & $3663(21.4 \%)$ & $1004(26.9 \%)$ & $<0.001$ \\
\hline Secondary & $12104(70.7 \%)$ & $2521(67.5 \%)$ & \\
\hline Tertiary & $1348(7.9 \%)$ & $210(5.6 \%)$ & \\
\hline \multicolumn{4}{|l|}{ Employment status } \\
\hline No & 11455 (62.6\%) & $2890(70.2 \%)$ & $<0.001$ \\
\hline Yes & $6849(37.4 \%)$ & $1226(29.8 \%)$ & \\
\hline \multicolumn{4}{|l|}{ Asset based SES } \\
\hline Low SES & $10856(54.7 \%)$ & 2797 (62.1\%) & $<0.001$ \\
\hline HIGH SES & $9003(45.3 \%)$ & 1708 (37.9\%) & \\
\hline \multicolumn{4}{|l|}{ Locality type } \\
\hline Urban formal & $11080(55.2 \%)$ & 2346 (51.5\%) & $<0.001$ \\
\hline Urban informal & $2159(10.8 \%)$ & $618(13.6 \%)$ & \\
\hline Rural informal & $4696(23.4 \%)$ & $1184(26.0 \%)$ & \\
\hline Rural formal & $2148(10.7 \%)$ & $408(9.0 \%)$ & \\
\hline
\end{tabular}




\begin{tabular}{|llll|}
\hline Alcohol use AUDIT score & $11466(64.0 \%)$ & $2727(66.6 \%)$ & $<0.001$ \\
\hline Lowstainers & $4759(26.6 \%)$ & $812(19.8 \%)$ & \\
\hline High risk drinkers (8-19) & $1498(8.4 \%)$ & $451(11.0 \%)$ & \\
\hline Hazardous drinkers 20+) & $198(1.1 \%)$ & $107(2.6 \%)$ & $<0.001$ \\
\hline Self-rated health & & & \\
\hline Fair/poor & $4149(20.7 \%)$ & $1631(35.9 \%)$ & $<0.001$ \\
\hline Good/excellent & $15872(79.3 \%)$ & $2906(64.1 \%)$ & \\
\hline Ever had HIV test & & & $<0.001$ \\
\hline No & $7372(36.8 \%)$ & $1515(33.4 \%)$ & \\
\hline Yes & $12637(63.2 \%)$ & $3023(66.6 \%)$ & $<0.001$ \\
\hline Awareness of HIV status & & & \\
\hline No & $12045(60.8 \%)$ & $2614(58.1 \%)$ & \\
\hline Yes & $7769(39.2 \%)$ & $1885(41.9 \%)$ & \\
\hline Self-perceived Risk of HIV Infection & & & \\
\hline No & $3995(20.1 \%)$ & $1153(25.7 \%)$ & \\
\hline Yes & $15896(79.9 \%)$ & $3341(74.3 \%)$ & \\
\hline Externalised HIV related stigma & & & \\
\hline No & $9606(48.2 \%)$ & $2193(48.5 \%)$ & \\
\hline Yes & $10312(51.8 \%)$ & $2326(51.5 \%)$ & \\
\hline
\end{tabular}

Table 2: Model of the relationship of psychological distress with socio-demographic, health and HIVrelated variables 


\begin{tabular}{|c|c|c|c|c|}
\hline Psychological distress & OR & \multicolumn{2}{|c|}{$95 \% \mathrm{Cl}$} & p-value \\
\hline \multicolumn{5}{|l|}{ Age categories } \\
\hline $15-24$ & Ref & & & \\
\hline 25 to 49 & 1.49 & 1.33 & 1.67 & $<0.001$ \\
\hline $50+$ & 1.42 & 1.23 & 1.63 & $<0.001$ \\
\hline \multicolumn{5}{|l|}{ Sex } \\
\hline Male & Ref & & & \\
\hline Female & 1.63 & 1.48 & 1.80 & $<0.001$ \\
\hline Marital status & Ref & & & \\
\hline \multicolumn{5}{|l|}{ Not married } \\
\hline Married & 0.80 & 0.72 & 0.89 & $<0.001$ \\
\hline \multicolumn{5}{|l|}{ Race } \\
\hline African & Ref & & & \\
\hline Other & 0.53 & 0.47 & 0.60 & $<0.001$ \\
\hline \multicolumn{5}{|l|}{ Educational level } \\
\hline Primary & Ref & & & \\
\hline Secondary & 0.88 & 0.79 & 0.98 & 0.004 \\
\hline Tertiary & 0.70 & 0.57 & 0.87 & $<0.001$ \\
\hline \multicolumn{5}{|l|}{ Employment status } \\
\hline \multicolumn{5}{|l|}{ No } \\
\hline Yes & 0.78 & 0.70 & 0.86 & $<0.001$ \\
\hline \multicolumn{5}{|l|}{ Asset based SES } \\
\hline Low & ref & & & \\
\hline high & 1.01 & 0.90 & 1.14 & 0.884 \\
\hline \multicolumn{5}{|l|}{ Locality type } \\
\hline Urban formal & Ref & & & \\
\hline Urban informal & 0.97 & 0.84 & 1.13 & 0.686 \\
\hline Rural informal & 0.78 & 0.68 & 0.89 & $<0.001$ \\
\hline Rural formal & 0.79 & 0.66 & 0.92 & 0.002 \\
\hline
\end{tabular}




\begin{tabular}{|lllll|}
\hline Alcohol use AUDIT score & & & & \\
\hline Abstainers & Ref & & & \\
\hline Low risk drinkers (1-7) & 0.90 & 0.81 & 1.01 & 0.071 \\
\hline High risk drinkers (8-19) & 1.88 & 1.61 & 2.20 & $<0.001$ \\
\hline Hazardous drinkers 20+) & 4.43 & 3.12 & 6.27 & $<0.001$ \\
\hline Self-rated health & & & & \\
\hline Fair/poor & Ref & & & \\
\hline Good/excellent & 0.40 & 0.37 & 0.45 & $<0.001$ \\
\hline Ever test for HIV & & & & \\
\hline No & & & & \\
\hline Yes & & & & \\
\hline Awareness of HIV status & 1.16 & 1.04 & 1.29 & 0.008 \\
\hline No & & & & \\
\hline Yes & Ref & & & \\
\hline Self-perceived risk of HIV & 1.02 & 0.91 & 1.13 & 0.786 \\
\hline No & & & & \\
\hline Yes & Ref & & & \\
\hline Externalised HIV related stigma & & & & \\
\hline No & 0.92 & 0.82 & 1.02 & 0.111 \\
\hline Yes & 0.93 & 0.85 & 1.02 & 0.111 \\
\hline
\end{tabular}

Table 3: Model of the relationship of the mediator variable HIV status with socio-demographic, health and HIV related variables 


\begin{tabular}{|lllll|}
\hline HIV status & OR & $95 \% \mathrm{Cl}$ & p-value \\
\hline Age categories & & & & \\
\hline $15-24$ & ref & & & \\
\hline 25 to 49 & 3.84 & 3.29 & 4.47 & $<0.001$ \\
\hline $50+$ & 1.50 & 1.21 & 1.87 & $<0.001$ \\
\hline Sex & & & & \\
\hline Male & Ref & & & \\
\hline Female & 1.57 & 1.37 & 1.80 & $<0.001$ \\
\hline Marital status & & & & \\
\hline Not married & ref & & & \\
\hline Married & 0.41 & 0.36 & 0.48 & $<0.001$ \\
\hline Race & & & & \\
\hline African & 1.60 & 1.31 & 1.94 & $<0.001$ \\
\hline Other & & & & \\
\hline Education status & ref & & & \\
\hline Primary & 0.19 & 0.15 & 0.23 & $<0.001$ \\
\hline Secondary & & & & \\
\hline Tertiary & & & & \\
\hline Employment status & & & & \\
\hline No & & & & \\
\hline Yes & & & & \\
\hline Asset based SES & 0.94 & 0.82 & 1.09 & 0.416 \\
\hline Low & & & & \\
\hline High & 0.94 & 0.82 & 1.09 & 0.416 \\
\hline Locality type & 0.32 & 0.59 & $<0.001$ \\
\hline Urban formal & & & & \\
\hline Urban informal & & & & \\
\hline
\end{tabular}




\begin{tabular}{|lllll|}
\hline Alcohol use AUDIT score & & & & \\
\hline Abstainers & ref & & & \\
\hline Low risk drinkers (1-7) & 0.93 & 0.81 & 1.08 & 0.358 \\
\hline High risk drinkers (8-19) & 1.00 & 0.80 & 1.25 & 0.967 \\
\hline Hazardous drinkers 20+) & 1.50 & 0.92 & 2.44 & 0.102 \\
\hline Self-related Health & & & & \\
\hline No & Ref & & & \\
\hline Yes & 0.68 & 0.59 & 0.78 & $<0.001$ \\
\hline Ever test for HIV & & & & \\
\hline No & Ref & & & \\
\hline Yes & 2.15 & 1.83 & 2.54 & $<0.001$ \\
\hline Awareness of HIV status & & & & \\
\hline No & Ref & & & \\
\hline Yes & 0.75 & 0.66 & 0.86 & $<0.001$ \\
\hline Self-perceived risk of HIV & & & & \\
\hline No & Ref & & & \\
\hline Yes & 0.41 & 0.36 & 0.46 & $<0.001$ \\
\hline Externalised HIV related stigma & & & & \\
\hline No & Ref & & & \\
\hline Yes & 1.24 & 1.10 & 1.39 & $<0.001$ \\
\hline
\end{tabular}

Table 4: The performance of the three fit statistics (Likelihood ratio, RMSEA, TLI, CFI.) 


\begin{tabular}{|lll|}
\hline Fit statistic & Value & Description \\
\hline Likelihood ratio & & \\
\hline chi2_ms (2) & 3161.428 & Model 1 vs. Model 2 \\
\hline $\mathrm{p}>$ chi2 & $<0.001$ & \\
\hline chi2_bs (11) & 3049.923 & baseline vs. saturated \\
\hline $\mathrm{p}>$ chi2 & $<0.001$ & \\
\hline Population error & & \\
\hline RMSEA & 0.000 & Root mean squared error of approximation \\
\hline $90 \%$ Cl, lower bound & $<0.001$ & \\
\hline upper bound & 0.000 & \\
\hline p-close & 1.000 & Probability RMSEA $<=0.05$ \\
\hline Baseline comparison & & \\
\hline CFI & 1.000 & Comparative fit index \\
\hline TLI & 1.000 & Tucker-Lewis index \\
\hline
\end{tabular}

\section{Figures}

\section{Figure 1}

Conceptual model of the relationship between psychological distress, mediator variable HIV status, sociodemographic, health and HIV-related variables

\section{Figure 2}

Final path model of the relationship between psychological distress, mediator variable, sociodemographic, health and HIV related variables 